\title{
The role of folate in the prevention of neural-tube defects
}

\author{
BY JOHN SCOTT ${ }^{1}$, PEADAR KIRKE ${ }^{3}$, ANNE MOLLOY ${ }^{2}$, \\ LESLIE DALY ${ }^{4}$ AND DONALD WEIR ${ }^{2}$ \\ Departments of ${ }^{1}$ Biochemistry and ${ }^{2}$ Clinical Medicine, Trinity College, Dublin, Republic of \\ Ireland, ${ }^{3}$ Health Research Board, Dublin, Republic of Ireland and ${ }^{4}$ Department of Public Health \\ Medicine, University College, Dublin, Republic of Ireland
}

Between days 24 and 28 post-conception the neural tube closes to form the spinal cord and the cranium. Incomplete closure of the former causes spina bifida and of the latter, anencephaly, the two conditions being collectively called neural-tube defects (NTD; O'Rahilly \& Muller, 1994). While there is clearly a genetic component to the aetiology of NTD the prevalence within any stable genetic pool varies significantly, indicating that other factors are involved. The other factor most commonly implicated is nutrition. Recently this area has advanced greatly with the now clear and universally accepted discovery that folate is this variable nutritional factor. As reviewed by Wald (1994), pteroylglutamic acid (folid acid) can prevent certainly over half, and in some studies all, NTD.

\section{HOW DOES FOLATE PREVENT NTD?}

The studies referred to previously were of two types and are summarized by Wald (1994) in a recent CIBA Symposium publication. Some eight prospective intervention trials have found that giving folic acid periconceptually to women dramatically reduced the prevalence of NTD. A different approach was used in some six studies that retrospectively examined the prevalence of NTD in women who happened to have been taking folic acid supplements compared with suitably matched controls not taking supplements. In all but one of these latter studies (Mills et al. 1989), there was a dramatic reduction in prevalence of NTD in the former group. In the intervention trials very large amounts of folic acid were used, from $400 \mu \mathrm{g}$ to $4.0 \mathrm{mg}$ daily. Similarly in the studies on the effect of folic acid supplements the amounts involved were $400 \mu \mathrm{g}$ folic acid daily. The recommended daily allowance for folate in most countries is about 200 to $300 \mu \mathrm{g} / \mathrm{d}$ (Bailey, 1994). In addition the mean dietary intake of folate in women of child-bearing age is under $200 \mu \mathrm{g} / \mathrm{d}$ (Hoppner et al. 1977). Both these latter values are for food folate which is perhaps half as bioavailable as folic acid, the synthetic form used in the studies mentioned previously (Gregory et al. 1991). Thus, it is clear that ingestion of $400 \mu \mathrm{g}$ folic $\mathrm{acid} / \mathrm{d}$ represents a vast increase in the intake of folate over what is usually available. This finding, therefore, presents two possible mechanisms whereby folic acid prevents NTD. Folic acid could be correcting deficiency of folate in these women or it could be overcoming a metabolic block in folate metabolism.

\section{NUTRITIONAL DEFICIENCY OR A METABOLIC BLOCK?}

A way of resolving which of these two aetiologies was operative seemed to us to determine folate status of women who had had an affected pregnancy and compare them with suitably collected controls who had had a normal pregnancy. It was clearly 
Table 1. Plasma folate, erythroycte folate and plasma cobalamin levels in mothers of children with neural-tube defects (cases) and in controls

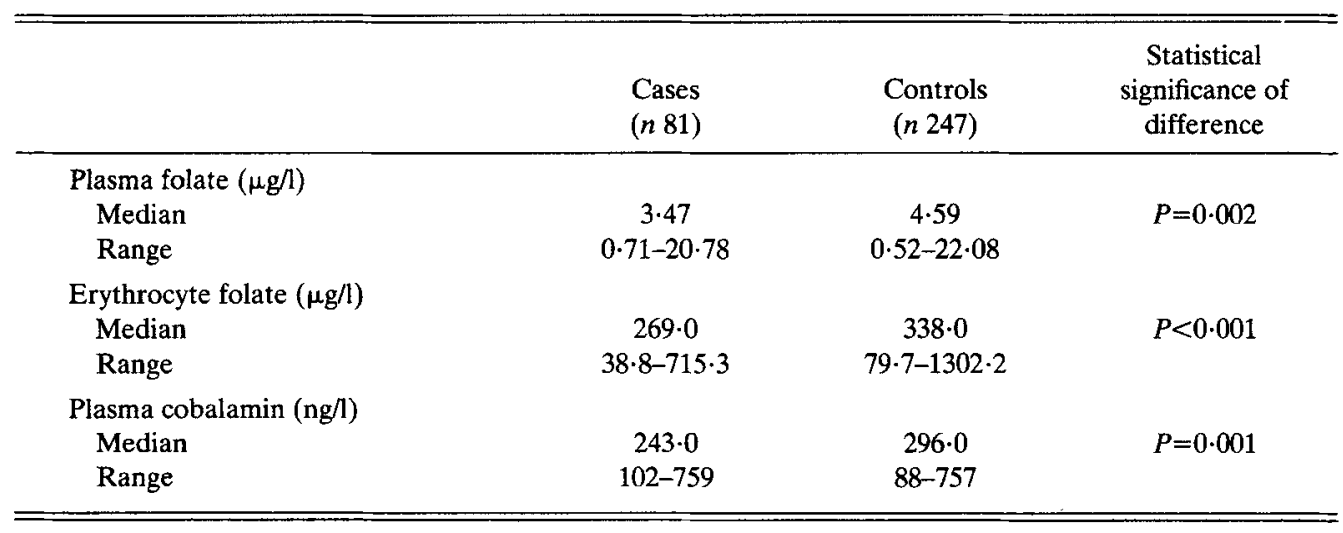

necessary to measure status in the pregnancy where neural-tube defective embryo had been produced. A suitable time at which status might be determined would be the first booking clinic.

With the assistance of the three Dublin maternity hospitals we collected plasma samples and samples prepared for erythrocyte folate analysis from 56049 women at such clinics over a 4-year period. This was a very representative population with about $70 \%$ of the pregnancies in these hospitals being involved. All samples were stored under identical conditions at $-20^{\circ}$. When pregnancy outcome became known it was possible to retrieve from this bank samples from eighty-one affected pregnancies (cases) and to select 247 normal pregnancies (controls) to cover the period of collection and storage. There was no selection bias between cases and controls nor was there any difference in their preparation or storage.

There are two methods of determining folate status. These are the estimation of (1) serum or plasma folate level and (2) erythrocyte folate level. The former fluctuates with recent dietary intake. Furthermore, values obtained at the first booking clinic, usually some 2 months into pregnancy, would have a doubtful relationship with what pertained at the closure of the neural tube. By contrast erythrocyte folates are made during the short period of erythrocyte maturation in the marrow, are a direct reflection of the plasma folate level at that time and do not change subsequently (Hoffbrand et al. 1966). They give, therefore, an average status over the $120 \mathrm{~d}$ life of the erythroycte and when taken at the first booking clinic could be expected faithfully to reflect folate status over the previous 4 months. Since the presence or absence of an NTD is not known at the first booking clinic it was necessary to collect samples from all women and await the outcome of the pregnancy some months later.

\section{PLASMA FOLATE, ERYTHROCYTE FOLATE AND PLASMA COBALAMIN IN CASES AND CONTROLS}

From Table 1 it can be seen that there were very significantly lower levels of plasma folate in cases, compared with controls. However, when these values were stratified into different ranges it was clear that the vast majority of cases were not folate deficient, i.e. 


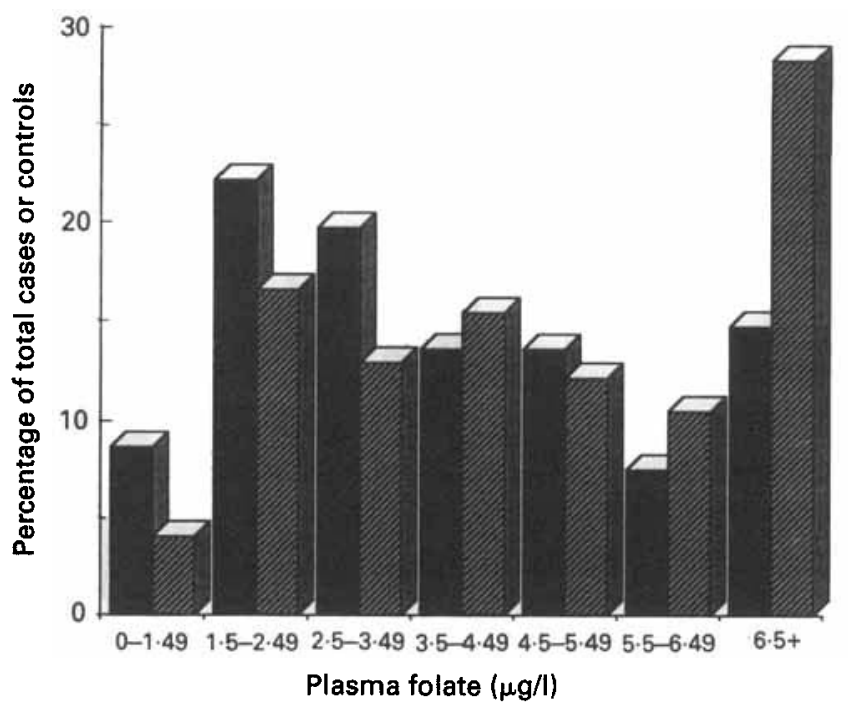

Fig. 1. The percentage distribution of neural-tube defect cases $(\boldsymbol{\square} ; n$ 81) and controls $(\mathbb{E} ; n 247)$, stratified with respect to their plasma pteroylglutamate (folate) levels.

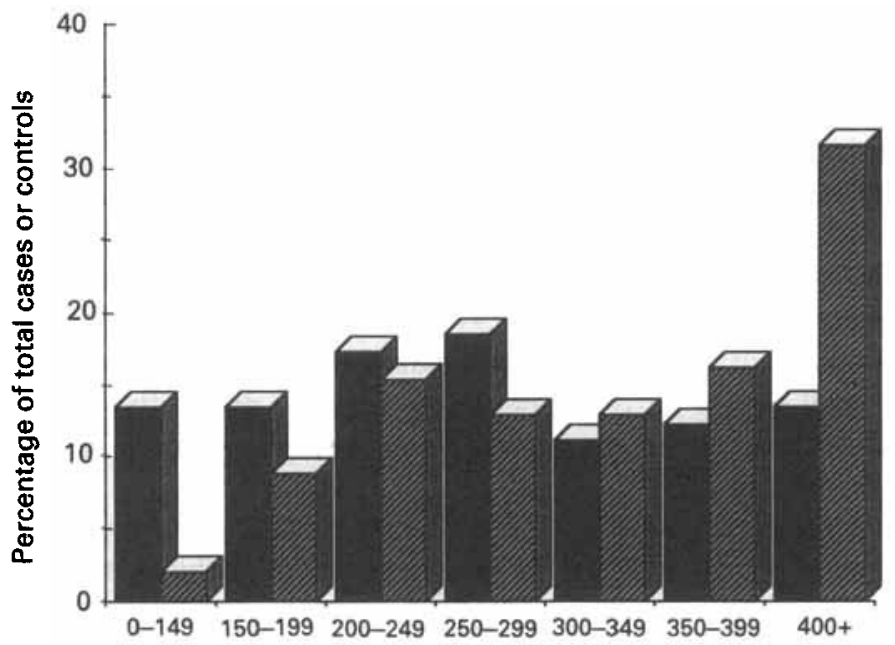

Erythrocytè folate $(\mu \mathrm{g} / \mathrm{l})$

Fig. 2. The percentage distribution of neural-tube defect cases $(\mathbf{\square} ; n 81)$ and controls $(\mathbb{K} ; n 247)$, stratified with respect to their erythroycte pteroylglutamate (folate) levels.

only $8.6 \%$ had a plasma folate level below $1.5 \mu \mathrm{g} / \mathrm{l}$ (Fig. 1) and $14.3 \%$ had erythrocyte folate levels below $150 \mu \mathrm{g} / \mathrm{l}$, the usual cut-off points for deficiency (Fig. 2). Only three cases had values where both indices were in the deficient range. This clearly indicates that the vast majority of women who go on to have an NTD-affected embryo in the same pregnancy are not folate deficient, and that the role of folic acid in prevention is that of overcoming a metabolic block in folate metabolism. 


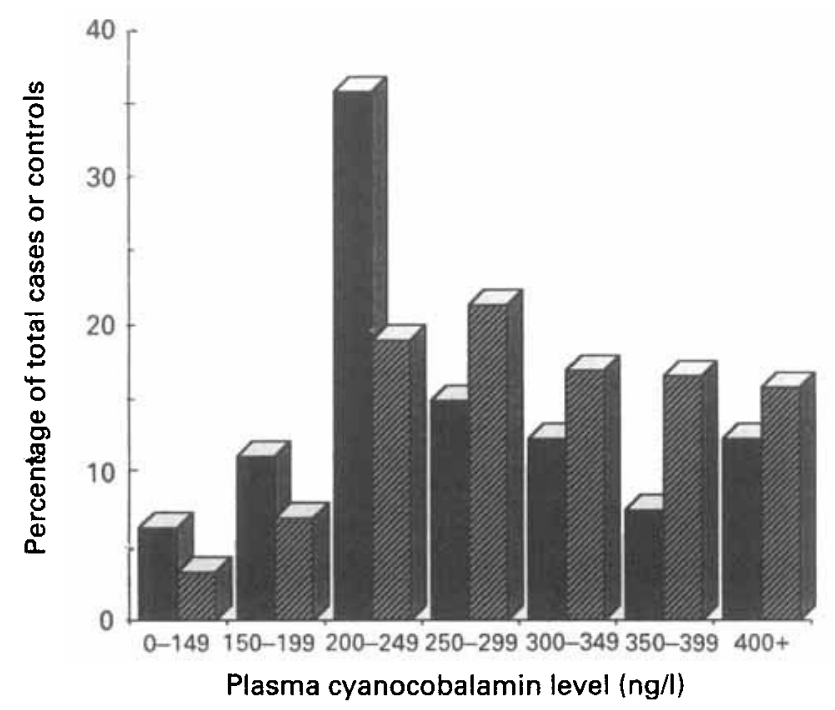

Fig. 3. The percentage distribution of neural-tube defect cases $(\mathbb{\square}, n 81)$ and controls $(\mathbf{D}, n$ 247), stratified with respect to their plasma cobalamin levels.

\section{WHERE IS THE METABOLIC BLOCK?}

There are about sixteen folate-dependent enzymes to choose from. However, we found that cobalamin status was an independent risk factor for NTD in our cases. As with plasma and erythrocyte folate, cobalamin levels were lower in cases than in controls (Table 1). With eight exceptions, the levels of cobalamin in the cases were in the normal range, i.e. above $150 \mu \mathrm{g} / \mathrm{l}$ (Fig. 3). However, logistic regression analysis showed plasma cobalamin status to predict risk independently of a woman's plasma folate and erythrocyte folate status (Kirke et al. 1993). If plasma cobalamin levels were reflecting difference in dietary intake and were correlated with risk because they simply mirrored folate intake, they would be dependent risk factors, which they are not. In addition, there was no correlation between plasma folate and plasma cobalamin in cases $(r 0.095)$ or controls ( $r$ 0.049; Fig. 4).

If the independent involvement of cobalamin in NTD can be confirmed by ourselves and others it would be significant in identifying the site of the metabolic block. Only one metabolic reaction is dependent on both folate and cobalamin, namely that catalysed by the enzyme methionine synthase (EC 2.1.1.13; Fig. 5). Our results suggest that direct or indirect malfunctioning of this enzyme is responsible for the majority of NTD.

\section{CONCLUSIONS}

The birth defects spina bifida and anencephaly collectively known as NTD are due, in the vast majority of cases, to a metabolic block in folate metabolism. This metabolic block can be overcome by the intake of high levels of folic acid periconceptually. The suggested involvement of cobalamin as a separate and independent risk factor for NTD indicates that the affected enzyme is methionine synthase, the only mammalian enzyme that uses both folate and cobalamin. 

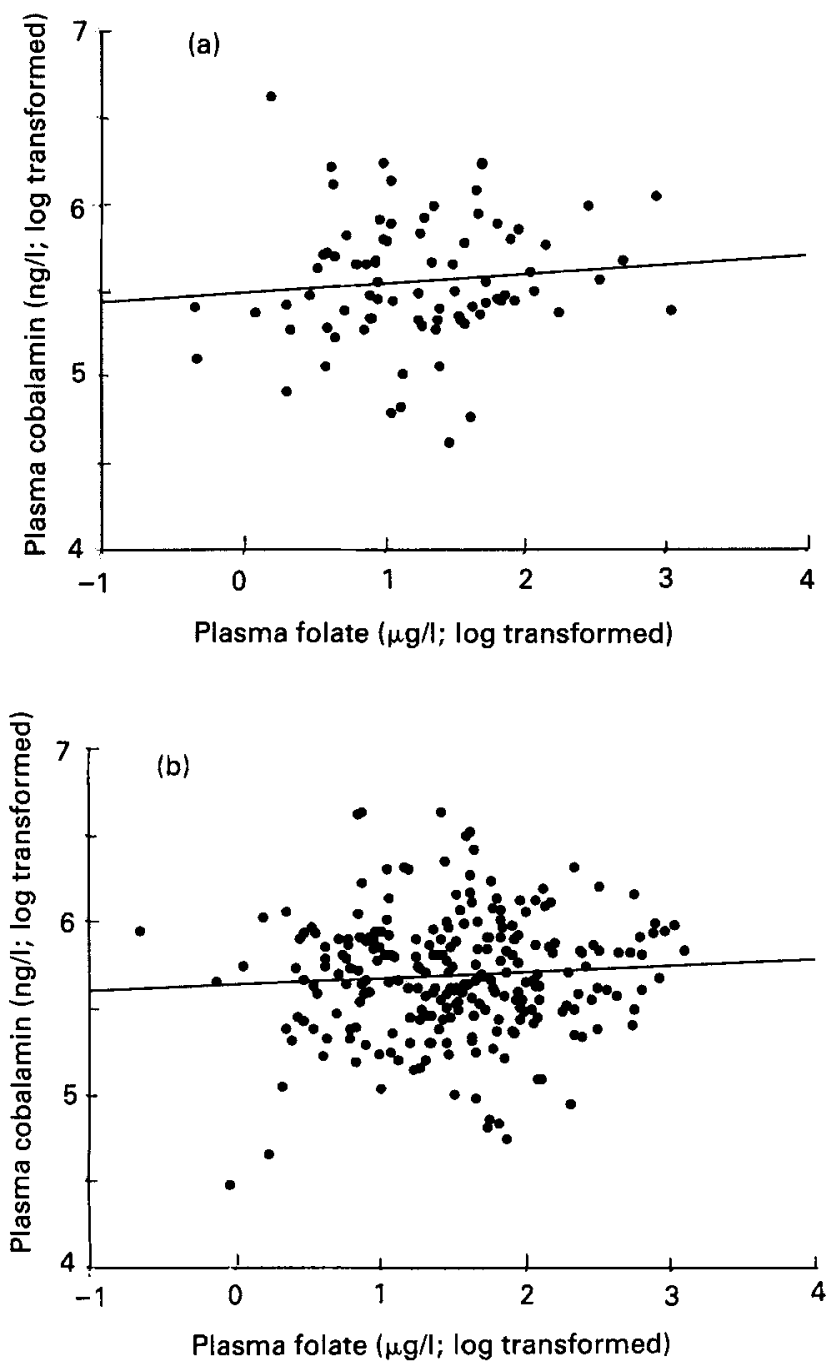

Fig. 4. The relationships between plasma cobalamin level and plasma folate level in (a) neural-tube defect cases and (b) controls. Cases: $r 0.095, P=0.60$ (not significant); controls: $r 0.049, P=0.55$ (not significant).

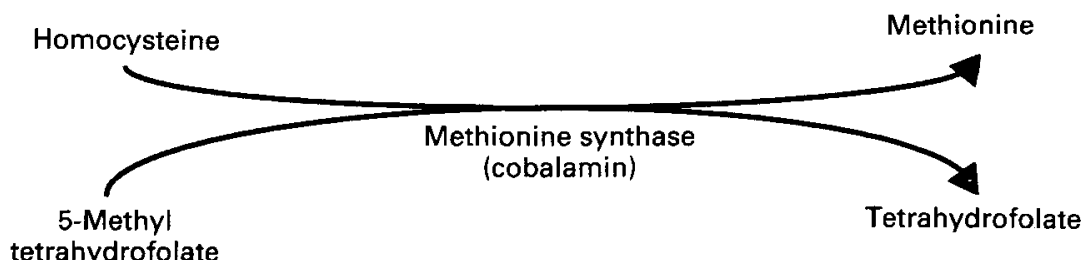

Fig. 5. The enzyme methionine synthase (EC 2.1.1.13) depends upon folate and cobalamin for its activity. 


\section{REFERENCES}

Bailey, L. B. (editor) (1994). Folate requirements and dietary recommendations. In Folate in Health and Disease. New York: Marcel Dekker (In the Press).

Gregory, J. F., Bhandari, S. D., Bailey, L. B., Toth, J. B., Baumgartner, T. G. \& Cerda, J. J. (1991). Relative bioavailability of deuterium-labeled monoglutamyl and hexaglutamyl folates in human subjects. American Journal of Clinical Nutrition 53, 736-740.

Hoffbrand, A. V., Newcombe, B. F. A. \& Mollin, D. L. (1966). Method of assay of red cell folate activity and the value of the assays as a test for folate deficiency. Journal of Clinical Pathology 19, 17-28.

Hoppner, K., Lampi, B. \& Smith, D. C. (1977). Data on folacin activity in foods: availability, applications and limitations. Folic Acid, Biochemistry and Physiology in Relation to Human Nutrition Requirements, pp. 69-81. Washington DC: National Academy of Sciences.

Kirke, P. N., Molloy, A. M., Daly, L. E., Burke, H., Weir, D. G. \& Scott, J. M. (1993). Maternal plasma folate and vitamin $B_{12}$ are independent risk factors for neural tube defects. Quarterly Journal of Medicine 86, 703-708.

Mills, J. L., Rhoads, G. G., Simpson, J. L., Cunningham, G. C., Conlon, M. R., Lassman, M. R., Walden, M. E., Depp, O. R. \& Hoffman, H. J. (1989). The absence of a relation between the periconceptional use of vitamins and neural tube defects. New England Journal of Medicine 321, 430-435.

O'Rahilly, R. \& Muller, F. (1994). Neurulation in the normal human embryo. CIBA Foundation Symposium 181, 70-89.

Wald, N. J. (1994). Folic acid and neural tube defects: the current evidence and implications for prevention. CIBA Foundation Symposium 181, 192-211. 